\title{
Stimulus Arrangement in Simple Discriminative Training with Compound and Emergence of Stimulus Equivalence Classes
}

\author{
Márcio Borges Moreira ${ }^{1}$ \\ University Center of Brasilia, Brasilia, DF, Brazil \\ Adriana Oliveira \\ University of Brasilia, Brasilia, DF, Brazil \\ Elenice S. Hanna \\ Department of Basic Psychological Processes, University of Brasilia, Brasilia, DF, Brazil
}

\begin{abstract}
Simple simultaneous discrimination training (SSD) with compound stimuli has produced variability in results of stimulus equivalence tests. This paper presents two studies investigating the role of methodological variables that alter the chance of control by aspects not defined as relevant for the formation of stimulus equivalence classes. Study 1 evaluated the effect of using an incorrect compound (S-) for each correct compound (S+) in each SSD trial that granted the conditional discrimination context without redundancy (e.g., A1B1 with A1B2 or A1B1 with A2B1). Five undergraduate students learned basic discriminations and showed symmetrical and transitive relations. The second study assessed the effect of a redundant element (a black spot) included on compounds of one of the classes in a training procedure of arbitrary conditional relations with SSD. The effects of this manipulation were investigated on performance of emergent relation tests, using MTS and SSD. All twelve students showed symmetrical relations, but only five showed transitive relations. These results expand the evidence that the configuration of training trials and irrelevant characteristics of stimuli may generate false positives in discriminative training.
\end{abstract}

Keywords: Simple simultaneous discrimination, compound stimuli, arbitrary emergent relations, undergraduate students.

\section{Arranjo de Estímulos em Treino Discriminativo Simples com Compostos e Emergência de Classes de Estímulos Equivalentes}

\section{Resumo}

O treino discriminativo simples simultâneo com compostos (DSSi) tem produzido variabilidade nos resultados de testes de estímulos equivalentes. O presente trabalho investigou em dois estudos o papel

Mailing address: University of Brasilia, Instituto de Psicologia, Departamento de Processos Psicológicos Básicos, Campus Universitário Darcy Ribeiro, ICC Norte, Asa Norte, Caixa-postal: 4500, Brasilia, DF, Brazil 70910-900. E-mail: borgesmoreira@gmail.com, oliveiradeadriana@gmail.com and hanna@unb.br

This study is part of the first author's doctorate thesis and the second author's Master's dissertation in the Postgraduate program of Behavioral Sciences at the University of Brasilia, under supervision by the third author. Adriana Oliveira was granted a Coordination for the Improvement of Higher Education Personnel (CAPES) scholarship for her Master. The authors are members of the National Institute of Science and Technology on Behavior, Cognition and Teaching, financed by National Counsel of Technological and Scientific Development - CNPq (Process \#573972/2008-7) and São Paulo Research Foundation - FAPESP (Process \#2008/57705-8), which supported the development of the studies. 
de variáveis metodológicas, que alteram as chances de controle por aspectos não definidos como relevantes, sobre a formação de classes de estímulos equivalentes. O Estudo 1 avaliou o efeito da utilização de um composto incorreto (S-) para cada composto correto ( $\mathrm{S}+$ ) em cada tentativa do DSSi que garantia o contexto de discriminação condicional sem redundância (e.g., A1B1 com A1B2 ou A1B1 com A2B1). Cinco estudantes universitários aprenderam as discriminações básicas e mostraram relações simétricas e transitivas. O Estudo 2 verificou o efeito da inclusão de um elemento redundante (mancha preta) nos compostos de uma das classes, utilizando um procedimento de treino de relações condicionais arbitrárias com DSSi. Avaliou-se os efeitos sobre os desempenhos nos testes de relações emergentes, utilizando-se MTS e DSSi. Os doze universitários mostraram relações simétricas, mas apenas cinco apresentaram relações transitivas. Esses resultados expandem as evidências de que configurações das tentativas de treino e as características irrelevantes dos estímulos podem gerar falso positivo nos treinos discriminativos.

Palavras-chave: Discriminações simples simultâneas, estímulos compostos, relações arbitrárias emergentes, estudantes universitários.

\section{Arreglo de Estímulo en Compuestos Simples con Entrenamiento Discriminativo y la Clase Equivalente de Estímulos}

\section{Resumen}

El entrenamiento discriminativo sencilla simultáneamente con compuestos (DSSi) han producido variabilidad en los resultados de las pruebas de estímulos equivalentes. Este estudio investigó en dos estudios el papel de las variables metodológicas que alteran las posibilidades de control por parte de los aspectos no definidos como relevantes, sobre la formación de las clases de equivalencia de estímulo. Estudio 1 evaluó el efecto del uso de un compuesto incorrecta $(\mathrm{S}+)$ para cada compuesto correcta $(\mathrm{S}+)$ en cada intento de garantía DSSi que el contexto discriminación condicional sin redundancia (por ejemplo, A1B1 con A1B2 A1B1 o con A2B1). Cinco estudiantes universitarios aprendieron la discriminación básica y mostraron relaciones simétricas y transitivas. El segundo estudio evaluó el efecto de la inclusión de un elemento redundante (punto negro) en los compuestos de una de las clases en un procedimiento de formación de las relaciones condicionales arbitrarias con DSSi. Se evaluó el efecto de esta manipulación sobre actuaciones en pruebas de relaciones emergentes, utilizando MTS y DSSi. Los doce estudiantes mostraron relaciones simétricas, pero sólo cinco tenido relaciones transitivas. Estos resultados amplían la evidencia de que los intentos de formación configuraciones y características irrelevantes de los estímulos pueden generar falsos positivos en la práctica discriminatoria.

Palabras clave: Discriminación simples concurrentes, compuestos de incentivos, emergentes relaciones arbitrarias, universidad estudiantes.

The term compound stimulus is used in the experimental research context to refer to the joint presentation, juxtaposition, or overlap of what has been conventionally called unitary stimuli (e.g., Grisante et al., 2013; Markham \& Dougher, 1993; Ray, 1969; Reynolds, 1961). However, experimental results have demonstrated that parts or properties of stimuli that are considered unitary may exert control over behavior (e.g., Lashley, 1938; Touchette, 1969), which suggests that the distinction between compound and unitary stimulus is arbitrary.

A series of studies have analyzed empirically and conceptually the stimulus equivalence paradigm (Sidman et al., 1982; Sidman \& Tailby, 1982) based on the notion that elements of a compound stimulus may be separated and recombined without disrupting discriminative control (cf., Stromer, McIlvane, \& Serna, 1993). Markham and Dougher (1993) and Stromer and 
Stromer (1990), for example, demonstrated the formation of stimulus equivalence classes by using a matching to sample procedure (MTS) where the stimuli used as samples were compound stimuli (a sound and a color) and the comparison stimuli were unitary stimuli (pictures). During symmetry and transitivity tests these stimuli were decomposed and presented separately, sometimes as samples and sometimes as comparisons, to evaluate the established conditional relations (see also, Carpentier, Smeets, \& Barnes-Holmes, 2000; Groskreutz, Karsina, Miguel, \& Groskreutz, 2010; Guerrero, Alós, \& Moriana, 2015; Maguire, Stromer, Mackay, \& Demis, 1994; Pérez-González \& Alonso-Álvarez, 2008; Ribeiro, Miguel, \& Goyos, 2015).

The formation of equivalence classes of stimuli was also demonstrated in studies that used compound stimuli in training sessions of simple simultaneous discriminations (SSD; e.g., Moreira \& Hanna, 2012; Smeets, BarnesHolmes, \& Cullinan, 2000) and simple successive discriminations (SSuD; e.g., Debert, Huziwara, Faggiani, de Mathis, \& McIlvane, 2009; Debert, Matos, \& McIlvane, 2007). In both cases, adult participants demonstrated the emergence of symmetry, transitivity, and symmetry of transitivity. Tests of emergence of relations with simple discrimination procedures (SSD and $\mathrm{SSuD}$ ) are carried out by recombining the elements of compound stimuli (e.g., if the compound $\mathrm{A} 1 \mathrm{~B} 1$ was established as $\mathrm{S}+, \mathrm{B} 1 \mathrm{~A} 1$ is used in the symmetry test).

Studies on stimulus equivalence classes generally use similar procedures for training and testing. For example, if a MTS procedure was used during training, the emergence of new relations during testing will also use this procedure. Moreira and Hanna (2012) appear to be the first researchers to use a different procedure for testing and training. The authors carried out two studies where participants went through SSD training with compound stimuli. In both studies, participants' emerging performance was tested with a SSD training procedure, as well as a MTS procedure. In Study 1, nine undergraduate students were submitted to training two $\mathrm{AB}$ discriminations and two $\mathrm{BC}$ discriminations using one correct compound stimulus $(\mathrm{S}+)$ and two incorrect compound stimuli (S-) in each trial. Correct compound stimuli were formed by components that belonged to the same stimulus set defined by the experimenter (e.g., A1B1), and incorrect compound stimuli were formed by components that belonged to different sets (e.g., A1B2). The S-s were the same in all training trials for each relation (e.g., $\mathrm{A} 1 \mathrm{~B} 2$ and $\mathrm{B} 2 \mathrm{~A} 1$, were present in all $A B$ Training trials). All participants attained the learning criterion established for trials (100\% correct responses in the last trial block of each training session), with few or no errors during the other trial blocks, demonstrating the emergence of the tested symmetrical relations. However, regarding transitivity and symmetry of transitivity tests, unlike Smeets et al. (2000, for adult participants), for example, "all-or-nothing" patterns $(100 \%$ correct responses or $0 \%$ correct) were observed within and between subjects, suggesting that the formation of equivalence classes with SSD procedures using compounds needs further investigation. The percentage of corrects responses for all the relations was similar for both test procedures (MTS and SSD).

According to Moreira and Hanna (2012), the variability in the results regarding the emergence of transitivity and symmetry of transitivity in Study 1, between and within-subjects, may have occurred, at least in part, due to the reduced number of S- (only two). The repetition of the same two $\mathrm{S}$ - in all training trials increases the chances of establishing control by rejection of $\mathrm{S}$-s or other spurious control. For example, in a trial with compounds A1B1 (S+), A1B2 (S-), and A2B1 (S-), the participant's behavior may be controlled by any compound that combines the most frequent elements from each trial (e.g., in a trial with A1B1, A1B2 and A2B1, choosing A1B1 because A1 as well as B1 appear twice) and not by the relation of S+ elements. However, it is not clear from Moreira and Hanna' study why these possible spurious controls would affect only the emergence of the transitivity and symmetry of transitivity relations.

In Study 2 by Moreira and Hanna (2012), which used the same training and testing structure as Study 1, five undergraduate students were submitted to training of three $\mathrm{AB}$ discriminations 
and three $\mathrm{BC}$ discriminations (compared to two $\mathrm{AB}$ discriminations and two $\mathrm{BC}$ discriminations in Study 1). Pairs of compound stimuli presented as S-s in each trial varied between training and testing trials due to a third set of stimuli being inserted, which increased the possible S- combinations from two to six (A1B2, A1B3, A2B1, $\mathrm{A} 2 \mathrm{~B} 3, \mathrm{~A} 3 \mathrm{~B} 1$ and $\mathrm{A} 3 \mathrm{~B} 2$, for $\mathrm{AB}$ training and $\mathrm{B} 1 \mathrm{C} 2, \mathrm{~B} 1 \mathrm{C} 3, \mathrm{~B} 2 \mathrm{C} 1, \mathrm{~B} 2 \mathrm{C} 3, \mathrm{~B} 2 \mathrm{C} 1$ and $\mathrm{B} 3 \mathrm{C} 2$ for $\mathrm{BC}$ training). All participants learned the taught relations with few or no errors, demonstrating the emergence of all tested relations. As in Study 1 , both test procedures (MTS or SSD) yielded high performance of all participants.

The studies conducted by Moreira and Hanna (2012) demonstrated the emergence of arbitrary conditional relations using two different testing procedures for the same participants and relations, but it was not possible to precisely identify the relevant variable that would explain the variability observed in Study 1 . The insertion of a third set of stimuli in Study 2 allowed the use of a larger number of S-s, but also increased, compared to Study 1, the number of programmed training trials from 152 to 234 . Extended exposure to the programmed reinforcement contingencies may have favored learning of programmed relations, yielding better performance in the transitivity and symmetry of transitivity tests.

In the present paper, based on issues raised by Moreira and Hanna (2012), two studies sought for additional evidence on important variables for the formation of stimulus equivalence classes through teaching simple discriminations with compound stimuli. Study 1 evaluated the effect of the configuration of training trials, by reducing the number of S- displayed in each trial. For Study 2, a spurious aspect was explicitly created (independently of compound elements) on one of the $\mathrm{S}+$ previously used in order to evaluate the formation of stimulus equivalence classes.

\section{Study 1}

Two studies that used SSD training with two compound stimuli reported divergent results. Smeets et al. (2000) showed the emergence of all tested relations with adults, while Moreira and Hanna (2012, Study 1) showed variability in the emergence of transitivity and symmetry of transitivity relations. In order to investigate the factors that generated different results in previous studies, the first study of the present work replicated Moreira and Hanna's Study 1, reducing the number of programmed S-s in each trial from two to one. This change allowed the S- in each set to be alternated between trials and made the procedure more similar to Smeets et al.

\section{Method}

\section{Participants}

Five undergraduate students participated in Study 1, one male and four females, aged from 22 to 57 years. Complementary activity credits were granted to subjects for participating in the study (one hour credit for each session). All of them signed the Informed Consent Form and the project was approved by the Ethics Committee for Research with Human Subjects of the Humanities Institute of the University of Brasilia.

\section{Experimental Environment, Equipment and Stimuli}

Experimental sessions occurred in soundproof experimental cabins measuring approximately $2 \times 2 \mathrm{~m}$. Each cabin had a desk, a chair and a micro-computer with a mouse, a keyboard, a monitor (15 or 17 inches), Windows $\mathrm{XP}{ }^{\circledR}$ operational environment and Internet Explorer ${ }^{\circledR}$ browser (version 6.0 or older). MTS DSSint 1.0 software (Moreira \& Hanna, 2012) ran the experimental task and recorded data.

Stimuli were abstract figures with low nameable aspects extracted from Nalini (2002). The figures measured approximately $2 \times 2 \mathrm{~cm}$ and were black on a white background. Stimuli used for an initial training task were selected from the Microsoft PowerPoint ${ }^{\circledR}$ auto shape database. Figure 1 shows the elements that composed the stimuli that were used as well as two examples of compound stimuli. Stimuli were displayed on the computer screen inside white rectangles measuring approximately $5.5 \mathrm{~cm}$ in length and 4 $\mathrm{cm}$ in height. A compound stimulus (e.g., A1B1) was created by presenting two unitary stimuli (e.g., A1 and B1), side-by-side, inside the white rectangle, as exemplified by Figure 1. 


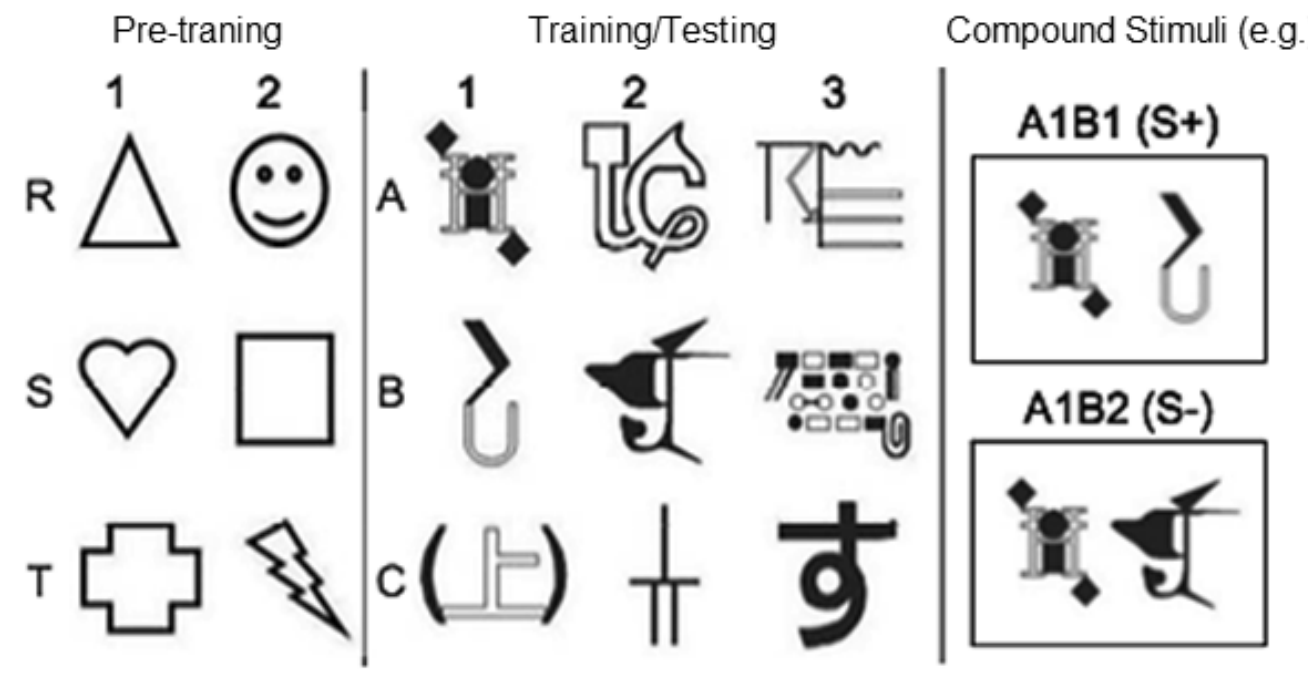

Figure 1. Elements and examples of compound stimuli used in Studies 1 and 2. Numbers (1, 2 and 3) designate the stimulus set and letters ( $A, B$ and $C)$ correspond to the exemplar of the set. Set 3 was used only in Study 2. Element A from Set 1, for example, is described in the paper as A1.

\section{Procedure}

Each participant went through three experimental session protocols, which consisted of SSD training followed by SSD and MTS tests in, at least, three sessions approximately 20 minutes long. The word "protocol" in this study refers to a specific sequence of discrimination training and testing trials that composed experimental sessions.

Protocol 1 comprised Pre-training, $\mathrm{AB}$ Training, BA Testing, A- $\mathrm{B}^{2}$ Testing and B-A Testing. Protocol 2 comprised BC Training, CB Testing, B-C Testing and C-B Testing. Protocol 3 comprised Mixed Training ( $\mathrm{AB}$ and $\mathrm{BC}$ relations), AC Testing, A-C Testing, CA Testing and $\mathrm{C}-\mathrm{A}$ Testing. Table 1 shows training and testing configurations of each session. $\mathrm{BA}, \mathrm{CB}$, $A C$ and $C A$ Tests used the SSD procedure and A-B, B-A, B-C, C-B, A-C and C-A Tests used MTS.

Pre-Training. Pre-training was programmed to familiarize with experimental task and used stimuli presented in the left panel of Figure 1. Participants were instructed to observe the

MTS training or testing procedures are indicated by letters separated by a hyphen (e.g., A-B) and SSD procedures are described by joined letters (e.g., AB). figures and click on one of them. They were informed that if their response was correct, the word "Correct" would appear on the screen. Pre-training consisted of 13 blocks with a similar number of trials and criteria as Training (described below), except for blocks were not repeated when errors occurred. Part of Pretraining (the five final blocks) used the MTS procedure with unitary stimuli (similar to the MTS test procedure described below, but with the addition of a differential consequence - the same one as described in the training procedures).

Training. Training occurred with a simple simultaneous discrimination (SSD) procedure with compound stimuli (Figure 2, left panel). Each training trial began by presenting one or two compound stimuli on a light blue background on the screen. When two compound stimuli were presented, one had the $\mathrm{S}+$ function and the other the S- (Table 1). Compound stimuli were displayed inside horizontal, side-by-side, vertically centralized, white rectangles, hereupon referred to as the display window. Placing the cursor within the limits of a window, would show a dark blue border approximately $2 \mathrm{~mm}$ wide, which would disappear when the cursor was moved outside the window or when the window was clicked on. Clicking on the window of the correct compound stimulus $(\mathrm{S}+$ ) produced 
the removal of the stimuli from the screen and the presentation of the word "CORRECT" for $1.5 \mathrm{~s}$. After this period, an intertrial interval (ITI) was active for $2.3 \mathrm{~s}$, during which the screen was brown. At the end of the ITI a new trial began. If the response occurred on the negative compound (S-), the trial ended and the ITT started with the brown screen and the trial was presented again

\section{SSD}

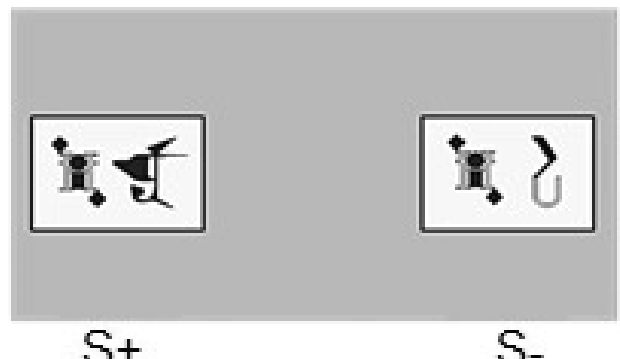

with the same stimuli in the same positions. The order of presentation of the different $\mathrm{S}+\mathrm{s}$, as well as $\mathrm{S}+$ and $\mathrm{S}-$ positions (left, center or right) were semi-random and the same $\mathrm{S}+$ was not presented for more than three consecutive trials, nor in the same position (the same order or presentation of trials per block was maintained for all participants).

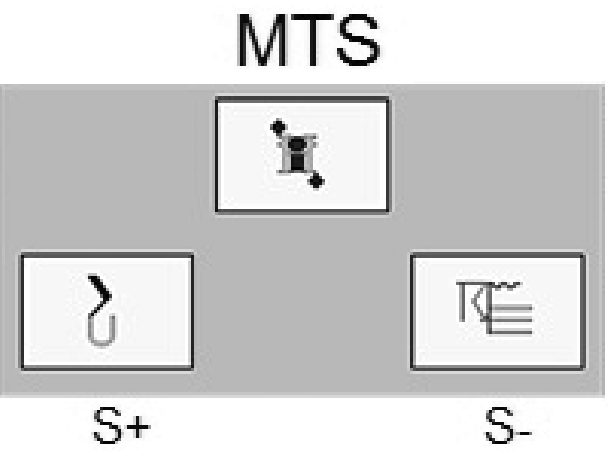

Figure 2. Stimulus presentation screen of one SSD trial and one MTS trial.

Training was organized in trial blocks with a gradual increase in the number of stimuli presented for each trial and the number of $\mathrm{S}+$ presented in each block (Table 1). For all training blocks, one or more errors produced the repetition of the block with a different presentation order. Consecutive errors in three blocks ended the session, which was repeated on another day from the beginning of the protocol, including the Pretest in the case of Protocol 1. Therefore, to finalize the training of a protocol the participant had to obtain $100 \%$ correct responses in all blocks.

$A B$ and $B C$ Training. $\mathrm{AB}$ and $\mathrm{BC}$ Training were programmed with the same structure, differing only in the relations trained (A1B1 and $\mathrm{A} 2 \mathrm{~B} 2$ in $\mathrm{AB}$ Training and $\mathrm{B} 1 \mathrm{C} 1$ and $\mathrm{B} 2 \mathrm{C} 2$ in $\mathrm{BC}$ Training). In the first trial of each training session, only the first $\mathrm{S}+$ was presented and in the following three blocks ( 2 to 4 , Table 1 ) an S- was presented with the $\mathrm{S}+$. Then, the same sequence was carried out with the second $\mathrm{S}+$ (blocks 5 to 7). In the last two blocks (9 and 10) all the $\mathrm{S}+$ and $\mathrm{S}-$ were alternated between trials (Table 1).

Mixed Training. During Mixed Training, each $\mathrm{S}+$ was presented by itself once (Block 1, Table 1). This was followed by a trial block with $\mathrm{AB}$ discriminations (Block 2), a block with $\mathrm{BC}$ discriminations (Block 3) and three blocks of mixed trials of $\mathrm{AB}$ and $\mathrm{BC}$ discriminations, all with one $\mathrm{S}+$ and one S- (blocks 4, 5 and 6). Block 6 was programmed in extinction, i.e., no consequence was planned for correct or incorrect responses. Before beginning this training session, the participant was warned, on the computer screen, that he or she would no longer be informed of correct answers.

$B A, C B, A C$ and $C A$ Testing. BA, CB, AC and CA Tests used a SSD procedure with compound stimuli (Figure 2), such as during training. Each test constituted a block with six trials (see Table 1), with three presentations of each tested relation (B1A1, B2A2, C1B1, C2B2, $\mathrm{A} 1 \mathrm{C} 1$, $\mathrm{A} 2 \mathrm{C} 2, \mathrm{C} 1 \mathrm{~A} 1$ and $\mathrm{C} 2 \mathrm{~A} 2$ ). The compound stimuli used in the SSD tests were a recombination of the compound stimuli used during training, alternating the relative position (left or right) of each element of the compound stimuli (e.g., B1A1, A1C1, C2A2). For each trial, clicking on any of the stimuli produced their removal from the screen (no differential consequence was programmed for correct and incorrect responses). After the stimuli removal, the ITI was active for $2.3 \mathrm{~s}$, during which the screen was brown. 
Table 1

Protocol of Training and Test Trials of Each Experimental Session Specifying Positive (S+) and Negative (S-) Stimuli and Number of Trials (NT) Programmed in Each Block (BI)

\begin{tabular}{|c|c|c|c|c|c|c|c|c|c|c|c|}
\hline \multicolumn{4}{|c|}{ Protocol 1} & \multicolumn{4}{|c|}{ Protocol 2} & \multicolumn{4}{|c|}{ Protocol 3} \\
\hline B1. & $\mathrm{S}+$ & S- & NT & Bl. & $\mathrm{S}+$ & S- & NT & B1. & $\mathrm{S}+$ & S- & NT \\
\hline \multicolumn{4}{|c|}{ Training AB } & \multicolumn{4}{|c|}{ Training BC } & \multicolumn{4}{|c|}{ Mixed Training AB/BC } \\
\hline 1 & A1B1 & - & 1 & 1 & $\mathrm{~B} 1 \mathrm{C} 1$ & - & 1 & 1 & A1B1 & - & 4 \\
\hline 2 & A1B1 & A1B2 & 4 & 2 & $\mathrm{~B} 1 \mathrm{C} 1$ & $\mathrm{~B} 1 \mathrm{C} 2$ & 4 & & $\mathrm{~A} 2 \mathrm{~B} 2$ & - & \\
\hline 3 & A1B1 & $\mathrm{A} 2 \mathrm{~B} 1$ & 4 & 3 & $\mathrm{~B} 1 \mathrm{C} 1$ & $\mathrm{~B} 2 \mathrm{C} 1$ & 4 & & $\mathrm{~B} 1 \mathrm{C} 1$ & - & \\
\hline \multirow[t]{2}{*}{4} & A1B1 & $\mathrm{A} 1 \mathrm{~B} 2$ & 6 & 4 & $\mathrm{~B} 1 \mathrm{C} 1$ & $\mathrm{~B} 1 \mathrm{C} 2$ & 6 & & $\mathrm{~B} 2 \mathrm{C} 2$ & - & \\
\hline & & $\mathrm{A} 2 \mathrm{~B} 1$ & & & & $\mathrm{~B} 2 \mathrm{C} 1$ & & 2 & A1B1 & $\mathrm{A} 1 \mathrm{~B} 2$ & 8 \\
\hline 5 & $\mathrm{~A} 2 \mathrm{~B} 2$ & - & 1 & 5 & $\mathrm{~B} 2 \mathrm{C} 2$ & - & 1 & & $\mathrm{~A} 2 \mathrm{~B} 2$ & $\mathrm{~A} 2 \mathrm{~B} 1$ & \\
\hline 6 & $\mathrm{~A} 2 \mathrm{~B} 2$ & A1B2 & 4 & 6 & $\mathrm{~B} 2 \mathrm{C} 2$ & $\mathrm{~B} 1 \mathrm{C} 2$ & 4 & 3 & $\mathrm{~B} 1 \mathrm{C} 1$ & $\mathrm{~B} 1 \mathrm{C} 2$ & 8 \\
\hline 7 & $\mathrm{~A} 2 \mathrm{~B} 2$ & $\mathrm{~A} 2 \mathrm{~B} 1$ & 4 & 7 & $\mathrm{~B} 2 \mathrm{C} 2$ & $\mathrm{~B} 2 \mathrm{C} 1$ & 4 & & $\mathrm{~B} 2 \mathrm{C} 2$ & $\mathrm{~B} 2 \mathrm{C} 1$ & \\
\hline \multirow[t]{2}{*}{8} & $\mathrm{~A} 2 \mathrm{~B} 2$ & A1B2 & 6 & 8 & $\mathrm{~B} 2 \mathrm{C} 2$ & $\mathrm{~B} 1 \mathrm{C} 2$ & 6 & 4 & A1B1 & $\mathrm{A} 1 \mathrm{~B} 2$ & 8 \\
\hline & & $\mathrm{A} 2 \mathrm{~B} 1$ & & & & $\mathrm{~B} 2 \mathrm{C} 1$ & & & $\mathrm{~A} 2 \mathrm{~B} 2$ & $\mathrm{~A} 2 \mathrm{~B} 1$ & \\
\hline \multirow[t]{2}{*}{9} & A1B1 & $\mathrm{A} 1 \mathrm{~B} 2$ & 8 & 9 & $\mathrm{~B} 1 \mathrm{C} 1$ & $\mathrm{~B} 1 \mathrm{C} 2$ & 8 & & $\mathrm{~B} 1 \mathrm{C} 1$ & $\mathrm{~B} 1 \mathrm{C} 2$ & \\
\hline & $\mathrm{A} 2 \mathrm{~B} 2$ & $\mathrm{~A} 2 \mathrm{~B} 1$ & & & $\mathrm{~B} 2 \mathrm{C} 2$ & $\mathrm{~B} 2 \mathrm{C} 1$ & & \multirow{5}{*}{$\begin{array}{l}5 \mathrm{e} \\
6^{*}\end{array}$} & $\mathrm{~B} 2 \mathrm{C} 2$ & $\mathrm{~B} 2 \mathrm{C} 1$ & \\
\hline \multirow[t]{4}{*}{10} & A1B1 & A1B2 & 12 & 10 & $\mathrm{~B} 1 \mathrm{C} 1$ & $\mathrm{~B} 1 \mathrm{C} 2$ & 12 & & A1B1 & $\mathrm{A} 1 \mathrm{~B} 2$ & 12 \\
\hline & $\mathrm{A} 2 \mathrm{~B} 2$ & $\mathrm{~A} 2 \mathrm{~B} 1$ & & & $\mathrm{~B} 2 \mathrm{C} 2$ & $\mathrm{~B} 2 \mathrm{C} 1$ & & & $\mathrm{~A} 2 \mathrm{~B} 2$ & $\mathrm{~A} 2 \mathrm{~B} 1$ & \\
\hline & & & & & & & & & $\mathrm{B} 1 \mathrm{C} 1$ & $\mathrm{~B} 1 \mathrm{C} 2$ & \\
\hline & & & & & & & & & $\mathrm{B} 2 \mathrm{C} 2$ & $\mathrm{~B} 2 \mathrm{C} 1$ & \\
\hline \multicolumn{4}{|c|}{ Test BA/B-A } & \multicolumn{4}{|c|}{ Test CB/C-B } & \multicolumn{4}{|c|}{ Test AC/A-C/CA/C-A } \\
\hline \multirow[t]{2}{*}{1} & B1A1 & B2A1 & 6 & 1 & $\mathrm{C} 1 \mathrm{~B} 1$ & $\mathrm{C} 1 \mathrm{~B} 2$ & 6 & 1 & $\mathrm{~A} 1 \mathrm{C} 1$ & $\mathrm{~A} 1 \mathrm{C} 2$ & 6 \\
\hline & $\mathrm{B} 2 \mathrm{~A} 1$ & B1A2 & & & $\mathrm{C} 2 \mathrm{~B} 2$ & $\mathrm{C} 2 \mathrm{~B} 1$ & & & $\mathrm{~A} 2 \mathrm{C} 2$ & $\mathrm{~A} 2 \mathrm{C} 1$ & \\
\hline \multirow[t]{2}{*}{2} & A1 & $\mathrm{B} 1$ & 6 & 2 & B1 & $\mathrm{C} 1$ & 6 & 2 & A1 & $\mathrm{C} 1$ & 6 \\
\hline & $\mathrm{A} 2$ & B2 & & & B2 & $\mathrm{C} 2$ & & & $\mathrm{~A} 2$ & $\mathrm{C} 2$ & \\
\hline \multirow[t]{4}{*}{3} & B1 & A1 & 6 & 3 & $\mathrm{C} 1$ & B1 & 6 & 3 & C1A1 & $\mathrm{C} 1 \mathrm{~A} 2$ & 6 \\
\hline & B2 & $\mathrm{A} 2$ & & & $\mathrm{C} 2$ & B2 & & & $\mathrm{C} 2 \mathrm{~A} 2$ & C2A1 & \\
\hline & & & & & & & & 4 & $\mathrm{C} 1$ & A1 & 6 \\
\hline & & & & & & & & & $\mathrm{C} 2$ & $\mathrm{~A} 2$ & \\
\hline
\end{tabular}

Note. All SSD trials displayed compound stimuli; MTS test trial displayed single stimuli as sample and comparisons. *Block 6 from Mixed Training (Protocol 3) was identical to Block 5, except for the absence of differential consequences.

$A-B, B-A, B-C, C-B, A-C$ and $C-A$ Testing. A-B, B-A, B-C, C-B, A-C and C-A Tests used a MTS procedure with unitary stimuli (Figure 2), always with two choices. In the MTS tests, the compound stimuli used in training were presented separately (e.g., B1 presented as sample and $\mathrm{A} 1$ as the comparison; Table 1). Each test was composed of a block with six trials (Table 1 ), and each tested relation was presented three times (A1-B1, A2-B2, B1-A1, B2-A2, B1-C1, B2-C2, C1-B1, C2-B2, A1-C1, A2-C2, C1-A1 and $\mathrm{C} 2-\mathrm{A} 2$ ).
MTS test trials began with the presentation of a sample stimulus, centered at the top of the light blue screen (e.g., B1). Clicking on the sample stimulus produced an immediate and simultaneous presentation of two comparison stimuli, one positive and one negative (e.g., A1 e A2). For each trial, clicking on any of the comparison stimuli produced their removal from the screen, followed by $2.3 \mathrm{~s}$ ITI, during which the screen was brown.

If a participant, during $\mathrm{BA}, \mathrm{A}-\mathrm{B}, \mathrm{B}-\mathrm{A}, \mathrm{CB}$, $\mathrm{B}-\mathrm{C}$ and $\mathrm{C}-\mathrm{B}$ Testing, clicked on the $\mathrm{S}-$ in more 
than one trial for the same relation (e.g., trials where B1A1 was the $\mathrm{S}+$ ), tests were repeated after the Mixed Training, before the programmed tests for Protocol 3. For all tests, the learning criteria of $83.33 \%$ was used to determine whether tested relations emerged.

\section{Results}

The percentage of correct answers in training and testing are presented in Figure 3. The first three columns in each graph, in white, show the percentages of correct responses for each participant in the last block of each training session. All the participants obtained 100\% correct responses in the last block of $\mathrm{AB}, \mathrm{BC}$ and Mixed Training.
In the tests, all participants, except P03, presented $100 \%$ correct responses in all the symmetrical relations tested (BA, B-A, CB and $\mathrm{C}-\mathrm{B}$, Figure 3, gray columns). The percentages of correct responses in the emergence test of symmetrical relations of participants $\mathrm{P} 03$ and P09 refer to the re-test of these relations in Protocol 3. Participant P03 repeated Protocol 2 for not reaching the learning criterion during training. For the same reason, participants P01 and P07 repeated Protocol 1.

Participants P01 and P08 presented 100\% correct responses in all the transitivity and symmetry of transitivity tests. P3, P7 and P9 had correct percentages below $100 \%$ for some of the transitivity and symmetry of transitivity tests (Figure 3, black columns).

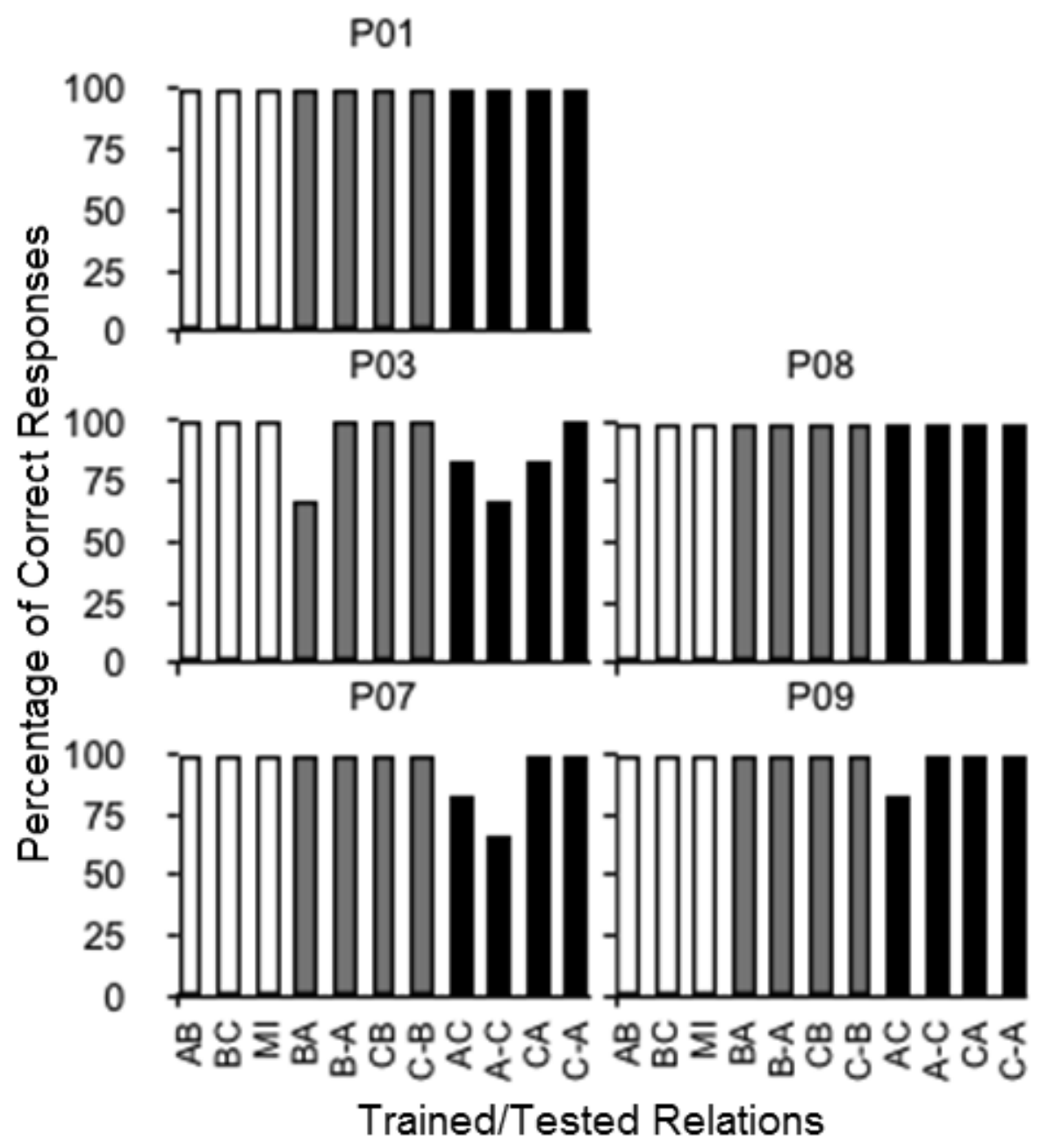

Figure 3. Percentage of correct responses in the last block from each training phase (AB, BC and Mixed-MI, white bars), in symmetry tests (Ba, B-A, CB, $\mathrm{C}-\mathrm{B}$, grey bars), and in transitivity tests (AC, A-C, CA e C-A, black bars), for each participant in Study 1. Joined letters (e.g., AB) indicate training/testing with the SSD procedure. Letters separated by a dash (e.g., A-B) indicate testing with the MTS procedure. 


\section{Discussion}

Results obtained in this study have shown the emergence of equivalence relations after training with a two-choice SSD procedure, which replicates Smeets et al. (2000) and diverges from results reported by Moreira and Hanna (2012). Our study suggests that variability in transitivity and symmetry of transitivity tests applied by Moreira and Hanna (2012, Study 1) occurred at least partially due to trial configuration (repetition of the same S- in every training trial). By reducing the number of S- from two to one per trial, we were able to present different $\mathrm{S}$ throughout trials.

Results from Study 1 of the present paper replicate and indicate the generality of results from Smeets et al. (2000) by demonstrating, with two different testing procedures (SSD and MTS), the emergence of symmetry, transitivity and symmetry of transitivity after SSD training.

\section{Study 2}

Non-relevant stimulus characteristics are mentioned in the discussion section of other studies as possible stimulus control sources that are not coherent with those programmed by the experimenter (e.g., Sidman, 1992) and that prevent systematic formation of stimulus equivalence classes. Except for some cases (e.g., McIlvane et al., 1987), the analysis of control relations that are different from those programmed by experimenters is conducted a posteriori. Study 2 was attained from the idea that it would be possible to program a stimulus arrangement to deliberately generate stimulus control topographies that are irrelevant in a procedure that produces positive results in tests. This arrangement should contain one characteristic with a probability of reinforcement that is similar to that programmed for the positive stimuli, thus named redundant characteristic. The chosen characteristic was a black spot added to the positive stimuli from a potential equivalence stimulus class. The spot was chosen as a redundant aspect due to the convenience of adding it to previously manufactured stimuli while maintaining all other procedural characteristics equal to the original study. The presence of the spot allowed correct responses to occur under its control; that is, it was unnecessary for behavior to be under control of the combination between elements of the positive stimuli $\mathrm{A} 1 \mathrm{~B} 1$ and $\mathrm{A} 1 \mathrm{C} 1$ that were also presented in every trial.

The procedure selected to replicate this study was used by Moreira and Hanna (2012, Study 2). Study 2 from Moreira and Hanna used a training and testing sequence that is similar to the one described in Study 1 of this paper, except that three stimulus equivalence classes, instead of two, composed of three stimuli each, were trained and tested. The chosen procedure permitted an inclusion of the redundant element (black spot) in the positive compounds of one of the potential equivalence classes. If the procedure from Study 1 in this paper were used, the presence of the spot in one of the classes would turn its absence in another class into an equally redundant characteristic. Adding the spot to the stimuli in only one class would allow us to evaluate whether its effects were restricted to that specific class or whether the remaining classes would also be affected.

The objective of this study was to evaluate the effect of teaching discriminations between compounds that included one redundant aspect regarding the equivalent stimulus classes that may be formed.

\section{Method}

\section{Participants}

Twelve female undergraduate students participated in Study 2 (ages varied from 19 to 26 years). Complementary activity credits were given to participants. All participants signed the Informed Consent Form and the project was approved by the Ethics Committee for Research with Human Beings from the Institute of Human Sciences at the University of Brasilia.

\section{Experimental Setting, Equipment and Stimuli}

Identical to those of Study 1. 


\section{Procedure}

The procedure used was identical to that used in Study 2 by Moreira and Hanna (2012), the only difference being a black spot added to $\mathrm{A} 1 \mathrm{~B} 1$ and $\mathrm{A} 1 \mathrm{C} 1$ compound stimuli, as shown in Figure 4 (the spot was not inserted in compounds $\mathrm{A} 2 \mathrm{~B} 2, \mathrm{~B} 2 \mathrm{C} 2, \mathrm{~A} 3 \mathrm{C} 3$ and $\mathrm{B} 3 \mathrm{C} 3$ ).

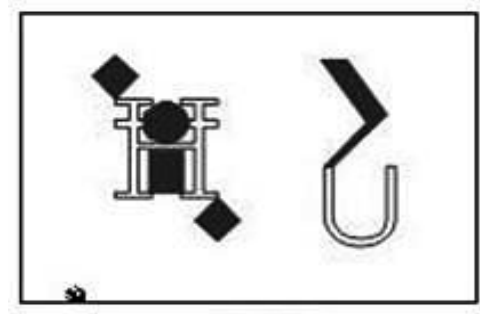

A1B1
The spot was not introduced in any of the test stimuli. The only criterion used for placing the spot in relation to the stimulus, inside the response window, was that it should be separated from the compound elements, since they were the same color. The relative position of the spot on each compound stimulus was the same for all trials (Figure 4).

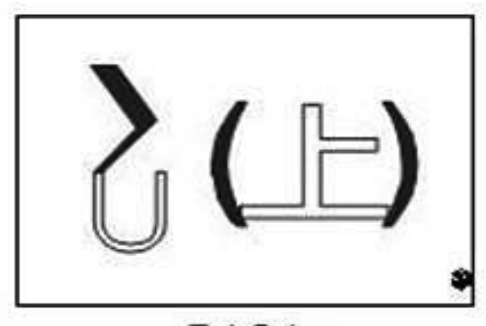

$\mathrm{B} 1 \mathrm{C} 1$

Figure 4. Compound stimuli with a spot added on the lower left of $\mathrm{A} 1 \mathrm{~B} 1$ and lower right of $\mathrm{B} 1 \mathrm{C} 1$.

Due to similarities between Study 1 of the present paper and Study 2 from Moreira and Hanna (2012) we may understand the procedure used here by describing the similarities and differences between both. Training and testing in each protocol described in Study 1 were the same, as well as instructions and the sequence of events that composed each training and testing trial. In the present study, however, we used three sets of stimuli with three members in each set, which implied on changing the composition of the training and testing blocks. In $\mathrm{AB}$ and $\mathrm{BC}$ Training, we presented only $\mathrm{A} 1 \mathrm{~B} 1$ and $\mathrm{B} 1 \mathrm{C} 1$ as positive compound stimuli in blocks 1 to $3, \mathrm{~A} 2 \mathrm{~B} 2$ and $\mathrm{B} 2 \mathrm{C} 2$ in blocks 4 to 6 , and $\mathrm{A} 3 \mathrm{~B} 3$ and $\mathrm{B} 3 \mathrm{C} 3$ in blocks 7 to 9 . In blocks 10 and 11, all positive and negative stimuli from their respective training alternated. In Mixed Training, they functioned as positive stimuli A1B1, A2B2 and $\mathrm{A} 3 \mathrm{~B} 3$ in blocks 1 to 3 and as $\mathrm{B} 1 \mathrm{C} 1, \mathrm{~B} 2 \mathrm{C} 2$ and $\mathrm{B} 3 \mathrm{C} 3$ in blocks 4 to 6 . From block 7 onwards, all positive and negative stimuli were presented in alternating trials, so the difference between blocks 8 and 9 was only the absence of feedback in the latter (extinction procedure). The number of S- available in each trial gradually increased from zero to two throughout blocks. For $A B$ Training, the S- used were A1B2, A1B3, A2B1,
$\mathrm{A} 2 \mathrm{~B} 3, \mathrm{~A} 3 \mathrm{~B} 1$ and $\mathrm{A} 3 \mathrm{~B} 2$; for $\mathrm{BC}$ Training, $\mathrm{B} 1 \mathrm{C} 2$, $\mathrm{B} 1 \mathrm{C} 3, \mathrm{~B} 2 \mathrm{C} 1, \mathrm{~B} 2 \mathrm{C} 3, \mathrm{~B} 2 \mathrm{C} 1$ and $\mathrm{B} 3 \mathrm{C} 2$ were used.

Testing was the same as in Study 1 of the present paper, except they used three sets of stimuli and each testing block was composed of six presentations of each tested relation, adding to 18 trials. In this study, the order of transitivity and symmetry tests was altered to AC, CA, A-C and C-A Testing.

\section{Results}

The percentage of correct responses in training and testing are presented in Figure 5. The first three columns of each graph, in white, show the percentage of correct responses for each participant in their last block of trial in each training phase. All participants scored $100 \%$ in the last block of $\mathrm{AB}, \mathrm{BC}$ and Mixed Training.

Results from symmetry tests (BA, B-A, $\mathrm{CB}, \mathrm{C}-\mathrm{B})$ are displayed in the grey columns and performance in transitivity and symmetry of transitivity tests are shown in the black columns in Figure 5. All participants, except P04, obtained $100 \%$ of correct responses, or proximal values, in all tests of emergence of symmetric relations. However, only participants P13, P16 and P18 presented emergence of 


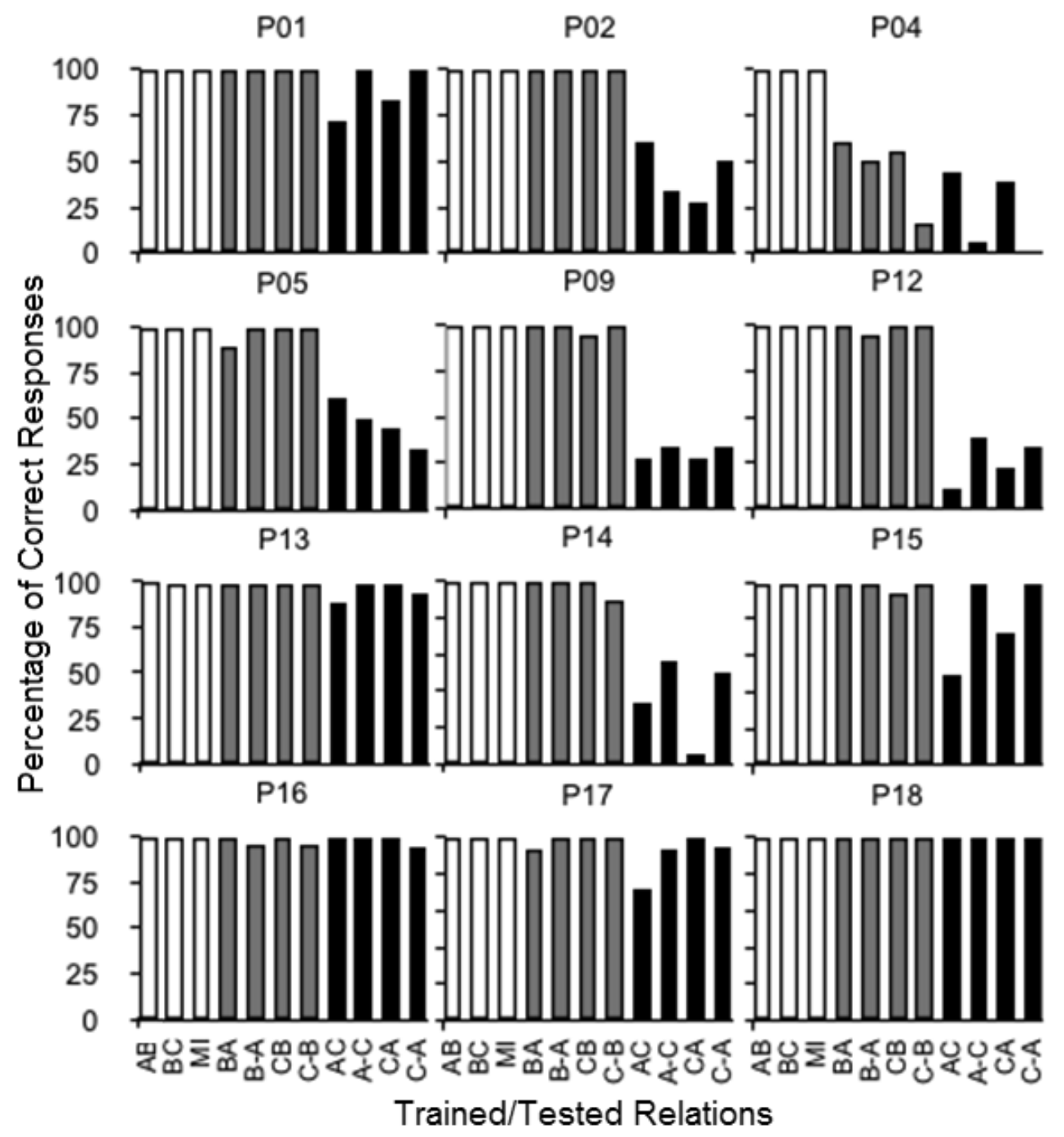

Figure 5. Percentage of correct responses in the last block from each training phase (AB, BC and Mixed-MI, white bars), in symmetry tests (BA, B-A, CB, C-B, grey bars), and in transitivity tests (AC, A-C, CA e C-A, black bars), for each participant in Study 2. Joined letters (e.g., AB) indicate training/testing with the SSD procedure. Letters separated by a dash (e.g., A-B) indicate testing with the MTS procedure.

all transitivity and symmetry of transitivity relations. The remaining participants presented low and variable performance in transitivity and symmetry of transitivity tests and there were no systematic differences that depended on the testing procedure (SSD or MTS).

Figure 6 shows the number of correct responses per relation for each participant in the transitivity and symmetry of transitivity tests. There were no systematic differences between performance in tests with Set 1 (which displayed a spot in training) and those without the spot (Sets 2 and 3).

Five out of twelve participants (41.7\% - P01, $\mathrm{P} 09, \mathrm{P} 15, \mathrm{P} 16$ and P18) responded according to relations defined by the experimenter in all trials or in five out of six trials with stimuli from Set 1. Six out of twelve participants (50\% - P01, P05, P13, P16, P17 and P18) responded according to the programmed relations in all trials or five out of six trials with stimuli from Set 3. Regarding Set 3, four out of twelve participants $(33.3 \%$ P13, P16, P17 and P18) responded according to relations programmed in all trials or in five out of six trials for this set of stimuli.

By comparing the number of errors committed in each test procedure, one may observe that five participants (P01, P09, P12, P13 and $\mathrm{P} 15)$ produced more errors in testing with SSD, three participants (P04, P05 and P17) had 
more errors in MTS tests and four participants (P02, P14, P16 and P18) had the same number of errors in both procedures. P16 and P18 made zero mistakes. Errors from all participants add up to 164 during SSD testing and 155 during MTS testing (each test, regardless of procedure, was composed of one block of 18 trials). The greatest number of errors occurred during SSD testing of Set 3. Analysis of participants' choices revealed control by stimulus-stimulus relations that were different among participants and from relations programmed by the experimenter. For example, $\mathrm{P} 09$ clicked on $\mathrm{A} 2 \mathrm{C} 3$ on six trials on which the S- was present. We did not observe systematic choice for negative compounds among participants.

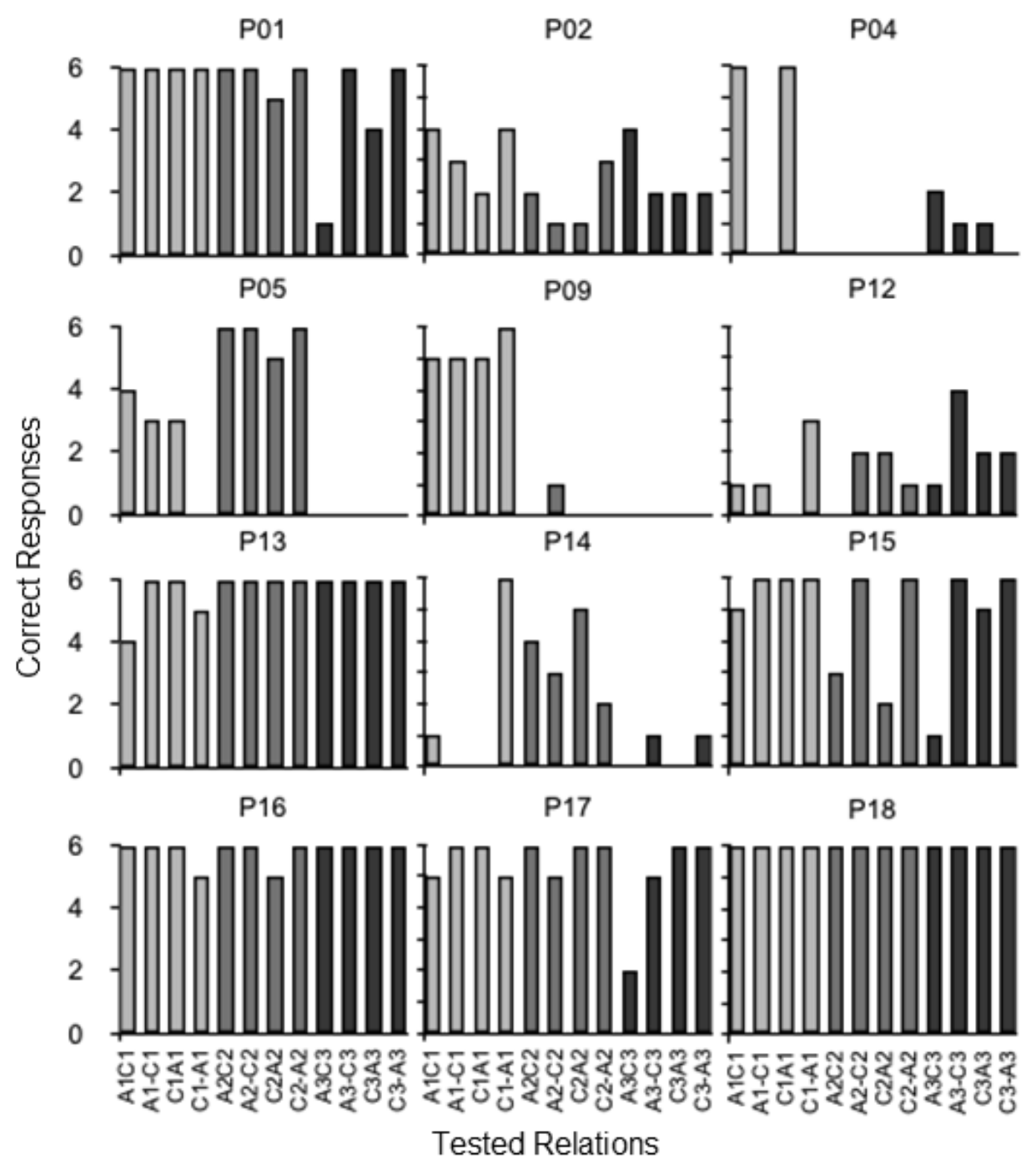

Figure 6. Number of correct responses per set in tests for the emergence of transitivity and symmetry of transitivity in Study 2. Joined letters (e.g., A1C1) indicate training/testing with the SSD procedure. Letters separated by a dash (e.g., A1-C1) indicate testing with the MTS procedure.

\section{Discussion}

In Study 2 by Moreira and Hanna (2012), five participants were exposed to SSD training with compound stimuli and a procedure that was similar to that used in this study. Emergence of symmetry, transitivity and symmetry of transitivity occurred for all participants for both SSD and MTS procedures. In the present study, which included a spot on stimuli from one of the taught classes (A1B1 and B1C1), only three participants (P13, P16 and P18) presented emergence 
of all transitivity and symmetry of transitivity relations. These results, when compared to results from Moreira and Hanna's Study 2, strongly suggest that the redundant characteristic presented during training of relations was effective in producing stimulus-stimulus control relations that were different to those programmed by the experimenter and, consequently, prevented the formation of stimulus equivalence classes (Dube \& McIlvane, 1996).

Except for P4, all participants demonstrated emergence of symmetry relations, which suggests that the spot did not have an effect on the emergence of those relations. This result replicates those reported by Moreira and Hanna (2012), Study 2. Since compound S+ stimuli were present in symmetry test trials, albeit in an inverse position, it is possible that they acquired some discriminative control, in addition to the spot. Tests with masks (Mcllvane et al., 1987) could be used in future studies to improve our comprehension of behavioral control by stimulus elements when the $\mathrm{S}+$, S- or part of them are covered with and without a spot.

An alternative explanation for high scores in symmetry tests would be to consider them as "false positive", and describing them as evidence for stimulus generalization (Smeets et al., 2000). Physical similarities between compound stimuli used in the symmetry tests with the SSD procedure and compound stimuli used in training (mirrored), may have been enough to control behavior through the new configuration. However, describing positive results in symmetry tests as stimulus generalization lead us to question whether the same description could be applied to MTS symmetry tests, in which the elements that composed the compound during training were separated and presented either as sample or as comparison stimuli (e.g., A1 and B1).

Although the spot has been inserted only in compound stimuli from Set 1 (A1B1 and $\mathrm{B} 1 \mathrm{C} 1$ ), it was observed variability in the emergence of transitivity and symmetry of transitivity relations for all three sets of stimuli. A possible explanation for the generalized effect of the spot may be on Sidman's (2000) suggestion that responses and reinforcement may also be included in equivalence classes. According to Sidman, if responses and reinforcement are part of equivalence relations, then responses and reinforcement which is common to two or more classes may generate one large equivalence class composed by all the elements (samples, comparisons, responses and reinforcement). When this large, single class is formed, performance in tests of relations emerging from smaller classes will be inconsistent and the results would be negative. Some individuals, however, may discriminate between classes even with responses and reinforcement in common. Sidman, as well as many results from the literature, point this out (e.g., Markham \& Dougher, 1993; Smeets et al., 2000; Stromer \& Stromer, 1990). To resolve this inconsistency, Sidman (2000) suggests that "the demands of the contingencies, however, must cause the response and reinforcer elements to drop out of that class eventually, making it possible for the smaller classes, A1B1C1 and A2B2C2, to form" (p. 132).

\section{General Discussion}

This paper presents two studies that investigated the effect of redundant characteristics in the configuration of training trials in the formation of stimulus equivalence classes using a SSD training procedure with compound stimuli. There is abundant evidence in the literature pointing out that discrimination programmed by experimenters are not always those learned by subjects (e.g., Dube et al., 2010; Dube \& Mcllvane, 1996; Lashley, 1938; Ray, 1969; Reynolds, 1961; Touchette, 1969). This phenomenon has been referred to in the literature as restricted stimulus control (Dube \& McIlvane, 1997) or stimulus overselectivity (Lovaas, Koegel, \& Schreibman, 1979).

Establishing stimulus control that is different to that programmed by the experimenter during discriminative training is, by itself, a legitimate research question when teaching discrimination is the phenomenon in question (e.g., Dube \& McIlvane, 1997). Moreover, establishing stimulus control topographies that are incongruent to those programmed by the 
experimenter is directly related to flaws in the emergence of stimulus equivalence classes (Dube \& McIlvane, 1996). Results obtained in the present work expand the body of evidence that the configuration of training trials and/ or stimulus characteristics may generate false positives in discriminative training and flaws in the emergence of transitivity and symmetry of transitivity relations (cf., Dube \& McIlvane, 1996) by demonstrating the occurrence of this phenomenon in discriminative training using a SSD procedure.

Results from Study 1 in this paper, when compared to results from Study 1 from Moreira and Hanna (2012), exemplify a case of identifying the development of incongruent stimulus control topographies a posteriori, such as is commonly found in the literature - that is, topographies are inferred after flaws are discovered in the formation of equivalence classes or identified after a new study or experiment is conducted. Thus, Study 2 in this paper presents a second potentially relevant contribution to the development of procedures that may help identify the incongruent stimulus control topographies during discriminative training tasks: inserting a redundant characteristic (a spot) on some of the stimuli.

Inserting a redundant characteristic in just one stimulus set, in Study 2, produced flawed emergence of transitivity and symmetry of transitivity relations in the other sets of stimuli. We were not able to identify, in the present work, which variables are responsible for these results, and Sidman's (2000) proposal described previously remains to be empirically tested. To identify such variables, an initial manipulation could consist in removing the training trials from Set 1 , but maintaining trials for this set during testing. Thus, one could evaluate whether flawed emergence in transitivity and symmetry of transitivity relations, in all three classes, are a function of displaying, during testing, trials with "non-related stimuli".

In Study 2, all three sets of stimuli required the same response which produced the same consequences. Creating a procedure that contem- plates the manipulation conducted in Study 2 and predicts different responses and consequences for the relations taught from each set seems promising to: (a) verify whether the effects of the manipulation in Study 2 are restricted to the class in which the spot was inserted and (b) test Sidman's (2000) aforementioned hypothesis (e.g., Dube \& McIlvane, 1995; Dube, McIlvane, Mackay, \& Stoddard, 1987; Garcia \& Benjumea, 2006; Urcuioli, Lionello-DeNolf, Michalek, \& Vasconcelos, 2006; Urcuioli \& Vasconcelos, 2008).

Results in the present paper corroborate results from Moreira and Hanna (2012) by demonstrating similar performances between participants in MTS and SSD testing after SSD training with compound stimuli. These results provide empirical support to the notion that elements in compound stimuli may be separated and recombined without ruptures in discriminative control (Debert et al., 2009; Debert, Matos, \& Andery, 2006; Debert et al., 2007; Markham \& Dougher, 1993).

As Debert et al. (2006) pointed out, it is impossible to identify conditional and discriminative functions of stimuli in training procedures using simple discriminations with compound stimuli. If this proposition proves true, it will be necessary to review the defining properties of equivalent stimulus classes. Symmetry, for instance, is defined based on inverting stimulus functions (discriminative and conditional). In the present work, such as Moreira and Hanna (2012), redundancies displayed during discriminative training have little to no effect on the socalled symmetric relations.

Both studies provide additional evidence that establishing control by undesired or nonprogrammed aspects of the environment may have a deleterious effect on relational and discriminative learning. In a natural situation, identifying and controlling all possible sources is not an easy task, if it is possible at all. Even so, broadening knowledge on conditions that improve desirable stimulus topographies is important and necessary to generate effective learning technologies. 


\section{References}

Carpentier, F., Smeets, P., \& Barnes-Holmes, D. (2000). Matching compound samples with unitary comparisons: Derived stimulus relations in adults and children. The Psychological Record, 50, 671-685. Retrieved from http://opensiuc.lib.siu.edu/cgi/viewcontent. cgi? article $=1440 \&$ context $=$ tpr

Debert, P., Huziwara, E. M., Faggiani, R. B., de Mathis, M. E. S., \& McIlvane, W. J. (2009). Emergent conditional relations in a go/no-go procedure: Figure-ground and stimulus-position compound relations. Journal of Experimental Analysis of Behavior, 92, 233-243. doi:10.1901/ jeab.2009.92-233

Debert, P., Matos, M. A., \& Andery, M. A. P. A. (2006). Discriminação condicional: Definições, procedimentos e dados recentes. Revista Brasileira de Análise do Comportamento, 2, 37 52. Retrieved from http://www.periodicos.ufpa. br/index.php/rebac/article/view/801/1111

Debert, P., Matos, M. A., \& McIlvane, W. (2007). Conditional relations with compound abstract stimuli using a go/no-go procedure. Journal of Experimental Analysis of Behavior, 87, 89-96. doi:10.1901/jeab.2007.46-05

Dube, W. V., Dickson, C. A., Balsamo, L. M., O’Donnell, K. L., Tomanari, G. Y., Farren, K. M., ...Mcllvane, W. J. (2010). Observing behavior and atypically restricted stimulus control. Journal of the Experimental Analysis of Behavior, 94, 297-313. doi:10.1901/ jeab.2010.94-297

Dube, W. V., \& McIlvane, W. J. (1995). Stimulusreinforcer relations and emergent matching to sample. The Psychological Record, 45, 591-612.

Dube, W. V., \& McIlvane, W. J. (1996). Some implications of a stimulus control topography analysis for emergent stimulus classes. In T. R. Zentall \& P. M. Smeets (Eds.), Stimulus class formation in humans and animals (pp. 197-218). Amsterdam, North Holland: Elsevier.

Dube, W. V., \& McIlvane, W. J. (1997). Reinforcer frequency and restricted stimulus control. Journal of Experimental Analysis of Behavior, 68, 303-316. doi:10.1901/jeab.1997.68-303

Dube, W. V., McIlvane, W. J., Mackay, H. A., \& Stoddard, L. T. (1987). Stimulus class membership established via stimulus-reinforcer relations. Journal of the Experimental Analysis of Behavior, 47, 159-175. doi:10.1901/ jeab.1987.47-159

Garcia, A., \& Benjumea, S. (2006). The emergence of symmetry in a conditional discrimination task using different responses as propioceptive samples in pigeons. Journal of the Experimental Analysis of Behavior, 86, 65-80. doi:10.1901/ jeab.2006.67-04

Grisante, P. C., Galesi, F. L., Sabino, N. M., Debert, P., Arntzen, E., \& McIlvane, W. J. (2013). Go/ no-go procedure with compound stimuli: Effects of training structure on the emergence of equivalence classes. The Psychological Record, 63, 63-72.

Groskreutz, N. C., Karsina, A., Miguel, C. F., \& Groskreutz, M. P. (2010). Using complex auditory-visual samples to produce emergent relations in children with autism. Journal of Applied Behavior Analysis, 43, 131-136. doi:10.1901/ jaba.2010.43-131

Guerrero, M., Alós, F. J., \& Moriana, J. A. (2015). Emergent relations with compound stimuli in conditional and simple discriminations: An experimental application in children. The Psychological Record, 65, 475-486. doi:10.1007/ s40732-015-0123-6

Lashley, K. S. (1938). The mechanism of vision: XV. Preliminary studies of the rat's capacity for detail vision. Journal of General Psychology, $18,123-193$.

Lovaas, O. I., Koegel, R. L., \& Schreibman, L. (1979). Stimulus overselectivity in autism: A review of research. Psychological Bulletin, 86, 1236-1254.

Maguire, R. W., Stromer, R., Mackay, H. A., \& Demis, C. A. (1994). Matching to complex samples and stimulus class formation in adults with autism and young children. Journal of Autism and Developmental Disorders, 24, 753772.

McIlvane, W. J., Kledaras, J. B., Munson, L. C., King, K. A., De Rose, J. C., \& Stoddard, L. T. (1987). Controlling relations in conditional discrimination and matching by exclusion. Journal of the Experimental Analysis of Behavior, 48, 187-208. doi:10.1901/jeab.1987.48-187

Markham, M., \& Dougher, M. J. (1993). Compound stimuli in emergent stimulus relations: Extending the scope of stimulus equivalence. Journal of 
the Experimental Analysis of Behavior, 60, 529542. doi:10.1901/jeab.1993.60-529

Moreira, M. B., \& Hanna, E. S. (2012). Emergência de classes de equivalência após separação e recombinação dos estímulos compostos utilizados no treino [Emengency of equivalence classes after separating and recombining training compound stimuli]. Revista Brasileira de Análise do Comportamento, 8, 59-80. Retrieved from http://www.periodicos.ufpa.br/index.php/rebac/ article/view/1922/2345

Nalini, L. E. (2002). Determinação empírica da nomeabilidade de estímulos: Implicações para o estudo da relação de nomeação [Empirical determination of stimulus nomeability] (Doctoral dissertation, Universidade de Brasília, DF, Brazil).

Pérez-González, L. A., \& Alonso-Álvarez, B. (2008). Common control by compound samples in conditional discriminations. Journal of the Experimental Analysis of Behavior, 90, 81-101. doi:10.1901/jeab.2008.90-81

Ray, B. A. (1969). Selective attention: The effects of combining stimuli which control incompatible behavior. Journal of the Experimental Analysis of Behavior, 12, 539-550. doi:10.1901/ jeab.1969.12-539

Reynolds, G. (1961). Attention in the pigeon. Journal of the Experimental Analysis of Behavior, 4, 203-208. doi:10.1901/jeab.1976.26-207

Ribeiro, D. M., Miguel, C. F., \& Goyos, C. (2015). The effects of listener training on discriminative control by elements of compound stimuli in children with disabilities. Journal of the Experimental Analysis of Behavior, 104, 48-62. doi:10.1002/jeab.161

Sidman, M. (1992). Adventitious control by the location of comparison stimuli in conditional discriminations. Journal of the Experimental Analysis of Behavior, 58, 173-182.

Sidman, M. (2000). Equivalence relations and the reinforcement contingency. Journal of the Experimental Analysis of Behavior, 74, 127-146. doi:10.1901/jeab.1992.58-173

Sidman, M., Rauzin, R., Lazar, R., Cunningham, S., Tailby, W., \& Carrigan, P. A. (1982). Search for symmetry in the conditional discriminations of rhesus monkeys, baboons, and children. Journal of the Experimental Analysis of Behavior, 37, 23-44. doi:10.1901/jeab.1982.37-23.
Sidman, M., \& Tailby, W. (1982). Conditional discrimination vs. matching to sample: An expansion of the testing paradigm. Journal of the Experimental Analysis of Behavior, 37, 5-22. doi:10.1901/jeab.1982.37-5

Smeets, P. M., Barnes-Holmes, D., \& Cullinan, V. (2000). Establishing equivalence classes with match-to-sample format and simultaneous-discrimination format conditional discrimination tasks. The Psychological Record, 50, 721-744. Retrieved from http://opensiuc.lib.siu.edu/cgi/ viewcontent.cgi? article $=1443 \&$ context $=\mathrm{tpr}$

Stromer, R., McIlvane, W., \& Serna, R. (1993). Complex stimulus control and equivalence. The Psychological Record, 43, 585-598.

Stromer, R., \& Stromer, J. (1990). The formation of arbitrary stimulus classes in matching to complex samples. The Psychological Record, 40, 51-66.

Touchette, P. E. (1969). Tilted lines as complex stimuli. Journal of the Experimental Analysis of Behavior, 12, 211-214. doi:10.1901/jeab.1969.12211

Urcuioli, P. J., Lionello-DeNolf, K., Michalek, S., \& Vasconcelos, M. (2006). Some tests of response membership in acquired equivalence classes. Journal of the Experimental Analysis of Behavior, 86, 81-107. doi:10.1901/jeab.2006.52-05

Urcuioli, P. J., \& Vasconcelos, M. (2008). Effects of within-class differences in sample responding on acquired sample equivalence. Journal of the Experimental Analysis of Behavior, 89, 341358. doi:10.1901/jeab.2008-89-341 